\title{
ANÁLISIS MUSICOLÓGICO POST MORTEM: COLOMBO A SANTO DOMINGO O LA ÓPERA DEL CENTENARIO
}

\author{
Armando Gómez Rivas \\ Conservatorio Nacional de Música, INBA
}

La evaluación anatómica no inicia con el cuerpo, sino en el lugar de los hechos.

En caso de muerte violenta o duda de criminalidad, la autopsia no requiere autorización familiar; es de Ley.

Más allá de la observación simple, para determinar signos externos de la muerte, es indispensable considerar la vestimenta del cadáver: moda, calidad de los accesorios y artículos que se puedan extraer de los bolsillos.

Al final, se toman medidas corporales y muestras toxicológicas del cuerpo desnudo. ${ }^{1}$

Fecha de recepción: 19 de agosto de 2019

Fecha de aceptación: 18 de septiembre de 2020

${ }^{1}$ Dramatización con base en Ángel Estébanez y Fidel Fernández, "La autopsia clínica: aspectos generales”, en Revista Española de Patología, 36 (2003), pp. 267-282. 
$\mathrm{F}^{112}$ de octubre de 1892 se celebró el Cuarto Centenario Cdel descubrimiento de América. En cuestiones artísticas, se programó la ópera Colombo a Santo Domingo (1892) de Julio Morales (1863-1945) como parte de la festividad. La Compañía de Ópera Italiana del empresario Napoleón Sieni se encargó de producir, dentro de su temporada anual, la opera prima de un joven y desconocido compositor. Si bien se trataba del hijo de Melesio Morales (1839-1908), sin duda el más destacado autor de melodramas en México, el resultado fue catastrófico. La representación más aristocrática y punto climático de la producción musical para la celebración fue retirada del programa después del estreno. Un silencio contundente que, en los fríos estantes de un archivo institucional, evoca la refrigeración artificial del vacío.

Las crónicas del Cuarto Centenario esparcieron tinta en la descripción de cualquier cantidad de aspectos biográficos y anecdóticos en torno a Cristóbal Colón. Los bosquejos en el diario El Siglo Diez y Nueve dejan ver la importancia del navegante en el cambio ideológico y la consolidación de México como nación. En el relato, la libertad religiosa y la transformación económica son aspectos que se relacionan con el trazo de nuevas rutas mercantes. La consumación se expone como un conjunto de adelantos científicos y tecnológicos: comodidades domésticas que llevan al perfeccionamiento de las ciudades que permitían especular en torno a la sociedad del porvenir. Se entiende así que la circunnavegación aventurada por Colón fue la iniciadora de una globalización en la que México jugaba un papel crucial. Al entrar a los elementos locales de la fiesta se lee:

En la mañana de hoy amaneció de gala la Ciudad. Todas las calles de la carrera, muy particularmente las de Plateros, San Francisco y Avenida Juárez, se veían adornadas profusamente y con buen gusto, rebosando en ellas una incontable muchedumbre, deseosa de ver el desfile de la comitiva. 
Una valla de infantería desplegada desde la Plaza Mayor hasta Buenavista, procuraba tener despejada y expedita la vía pública y se aprontó a rendir los honores que marca la Ordenanza cuando el Presidente y las personas que formaban su séquito pasaron frente a ella. [...] Conforme estaba anunciado en los programas, poco después de las 10:30 de la mañana de hoy, se dio principio a la fiesta inaugural de la estatua del célebre navegante genovés, en la Plazuela de Buenavista.

A la llegada del Señor Presidente los alumnos del Conservatorio de Música, acompañados de los de las Escuelas del Gobierno, cantaron el Himno Nacional. ${ }^{2}$

Las actividades de la celebración fueron registradas en todos los diarios capitalinos. Con mayor o menor detalle, las crónicas recrean batallones uniformados, carruajes lustrosos y muchedumbre. De forma similar, la nota citada antes permite deducir que la música acompañó los actos protocolarios solemnes. Sin duda, se trata de una reducción drástica que debe suprimirse. La participación musical en las festividades del Centenario no se centró en la entonación masiva del Himno Nacional. En realidad, la orquesta y el coro del Conservatorio de Música tuvieron un papel destacado en las presentaciones públicas. Entre las colaboraciones sobresalen la velada organizada por la Sociedad de Geografía y Estadística y, quizá más importante, el estreno de la ópera Colombo a Santo Domingo de Julio Morales en el Teatro Nacional. La función operística clausuró las actividades del Centenario. Es decir, el epítome acústico de 1892 fue el estreno de un drama lírico, relacionado con la gloria del navegante y escrito por un compositor nacional.

Si se reflexiona en torno al valor de la música en México durante el siglo XIX y de forma particular en la ópera, se puede llegar al hecho de estar frente a una manifestación de identidad:

2 “Las Fiestas del Centenario", El Siglo Diez y Nueve (12 oct. 1892), p. 1. 
escuchar un repertorio hermanaba oyente y grupo social. La pertenencia comprendía la aceptación de las connotaciones propias del género y los lugares comunes que dan origen a la tradición. En el drama musical, menciona el musicólogo Ricardo Miranda, "se veía el adelanto de un país, lo refinado de sus costumbres, lo excelso de sus mujeres, las finas maneras de sus prohombres, la educación, el buen gusto, y todo aquello que da prestigio y es motivo de orgullo" ${ }^{3}$ Un reflejo artístico de Europa que permitía la interacción aristocrática y al mismo tiempo conformaba una propuesta de nación. El proyecto, eso sí, tenía poco interés en incluir cuadros folclóricos indigenistas para simbolizar el desarrollo. La búsqueda era la imitación de las prácticas musicales transcontinentales.

Colombo a Santo Domingo significó, bajo estos términos, la confirmación de los avances de México. Una temporada de ópera en el Teatro Nacional -con una composición nacional-era la oportunidad para formar parte del mundo ilustrado. Pero, ¿ en qué medida se entendía un espectáculo tan grandioso? Primero, México lograba asimilar el longevo infortunio de la conquista de América para llevarlo a un escenario preclaro; despliegue de civilidad en un cuadro artístico. Segundo, la presentación permitía valorar la igualdad entre una partitura de autor mexicano y, dado que formaba parte de la temporada anual de una compañía itinerante europea, se evaluaba bajo los criterios más exquisitos de la práctica musical. Tercero, en el entendido de que se trataba de la partitura dramática del hijo de Melesio Morales -el más destacado operista que había dado el país-, se desprendía la posibilidad de presenciar una línea de sucesión creativa, reflejo ineludible del progreso.

Con estos antecedentes en mente, el Teatro Nacional y la Compañía de Ópera del empresario italiano Napoleón Sieni se sumaron al festejo con total autoridad la noche del 12 de octubre

${ }^{3}$ Miranda, “Identidad y cultura”, en Miranda y Tello, p. 28. 
de 1892. Para delimitar la expectativa relacionada con la música y la festividad, una semana previa al acontecimiento histórico, el crítico de El Correo Español apuntaba:

Se acerca el día memorable en que las naciones hispanoamericanas celebran el trascendental acontecimiento de la llegada del ilustre navegante Colón, a las playas del Continente Americano.

Asunto como este, debía inspirar necesariamente a poetas y a músicos, unos cantando en la inspirada lira que ha dado tantos acordes dulcísimos, y otros explotando temas musicales que inmortalizarán sin duda a sus autores.

No sabemos hasta ahora que en América haya habido otro eximio compositor, como lo es en México el señor Don Julio M. Morales, que en celebración del día mencionado, hubiese dado rienda suelta a su inspiración, traduciendo en hermosísimo poema musical, la llegada del inmortal navegante a estas feroces tierras; sólo al joven hijo de la gloria mexicana, Melesio Morales, cupo en suerte dar a la escena de la ópera en un acto bautizada con el nombre de "Cristóbal Colón” y la cual se cantará por la compañía de ópera 'Sieni' el 12 de Octubre próximo. ${ }^{4}$

Durante las últimas décadas del siglo xix, el empresario $\mathrm{Na}$ poleón Sieni sobresalió en el escenario capitalino de la ópera, más por la persistencia que por la calidad de las representaciones que ofrecía. Al ver la nómina de su Compañía resulta indiscutible que Sieni seguía la práctica de reclutar artistas capaces, pero debutantes. La realidad es que pocos de sus solistas transitaban en el círculo virtuoso de los teatros líricos europeos. Sin embargo, se debe acentuar como una cualidad singular, que cada año estrenaba una obra dramática no escuchada en México. ${ }^{5} \mathrm{Un}$

${ }^{4}$ Zil (seud.), “Ópera Mexicana. Cristóbal Colón”, El Correo Español (30 sep. 1892), p. 1. El artículo se repitió en El Tiempo (5 oct. 1892), p. 1.

5 Carmona, La música de México, p. 136. 
vistazo al repertorio para la temporada de 1892 permite deducir información trascendental relacionada con el gusto y las prácticas musicales en boga (véase la tabla 1). De inicio, se advierte que el empresario apostó por la tradición afirmada por el drama belcantista. No resulta extraño que la preferencia esté representada por las composiciones de Bellini, Donizetti, Rossini y Verdi. Melodías largas, acompañamientos simplificados y progresiones armónicas estáticas, e incluso reiterativas, constituyen la estructuración base. Al seguir la línea de los autores italianos, Giuseppe Verdi (1813-1901) se puede considerar el núcleo de la temporada: Aida (1871), Il Trovatore (1853), Ernani (1844), Rigoletto (1851), Un ballo in maschera (1859), La Traviata (1853) y Otello (1887). Más allá de conformar un muestrario estilístico del autor, la elección representaba tradición y buen gusto. Si se anticipa la lectura, el drama de Julio Morales se enfrentaría de forma ineludible a la comparación con las composiciones propuestas para la temporada.

Pero a la sonoridad de Verdi -como primer obstáculo a librar- se pueden añadir dos factores adicionales a los que se enfrentaría Morales: libreto y actualidad. En el caso del texto, las óperas seleccionadas muestran una inclinación hacia la invención fantástica; textos dramáticos basados en trabajos literarios de Dumas, Goethe, Shakespeare, Víctor Hugo y otros más. En oposición, el argumento de Colombo a Santo Domingo es de corte histórico y sólo se podría equiparar con Les Huguenots (1836); no obstante, la partitura de Giacomo Meyerbeer (17911864), que se sitúa en el París de 1572, se escribió para la Ópera de París y tiene una disposición arquitectónica distinta de la tradición italiana. Cavalleria Rusticana (1890) de Pietro Mascagni (1863-1945), por otra parte, resultaba la partitura más reciente y contrastante. Un drama lírico escrito pocos años antes, premiado en Europa e inmerso en el verismo. Es decir, el movimiento operístico de actualidad que olvidaba a los héroes románticos para transitar en lo cotidiano; la versión melodramática italiana 


\section{Tabla 1}

ÓPERAS REPRESENTADAS POR LA COMPAÑÍA SIENI

EN LA TEMPORADA DE 1892.

TEATRO NACIONAL DE LA CIUDAD DE MÉXICO

\begin{tabular}{lll}
\hline Obra & Autor & Género \\
\hline Aida & Giuseppe Verdi & Ópera (4 actos) \\
La Sonnambula & Vincenzo Bellini & Melodrama (2 actos) \\
Il Trovatore & Giuseppe Verdi & Drama (4 actos) \\
La Favorite & Gaetano Donizetti & Ópera (4 actos) \\
Lucia di Lammermoor & Gaetano Donizetti & Drama trágico (3 actos) \\
Guillermo Tell & Gioachino Rossini & Ópera (4 actos) \\
Fausto & Charles Gounod & Ópera (5 actos) \\
Ernani & Giuseppe Verdi & Drama lírico (4 actos) \\
Cavalleria Rusticana & Pietro Mascagni & Melodrama (1 acto) \\
Colombo a Santo Domingo & Julio Morales & Drama lírico (1 acto) \\
Rigoletto & Giuseppe Verdi & Melodrama (3 actos) \\
Un ballo in maschera & Giuseppe Verdi & Melodrama (3 actos) \\
La Gioconda & Amilcare Ponchielli & Drama Lírico (4 actos) \\
Les Hugnenots & Giacomo Meyerbeer & Gran ópera (5 actos) \\
La Traviata & Giuseppe Verdi & Ópera (3 actos) \\
Mefistofele & Arrigo Boito & Prólogo (5 actos) \\
Otello & Giuseppe Verdi & Drama lírico (4 actos) \\
\hline
\end{tabular}

del realismo. ${ }^{6}$ Pero más significativo, Mascagni modificó la estructura del género a un acto único. El conflicto y la brevedad de la vida -en este caso un triángulo amoroso- son reflejados en el escenario sin interpretaciones complejas, pues abandona la metafísica o cualquier postura filosófica para describir un adulterio con cierta crueldad.

Colombo a Santo Domingo de Julio Morales resultó el estreno de la temporada y su apreciación debió haber estado enmarcada en la lógica de la confrontación. Si la obra de moda era Cavalleria Rusticana, por qué no medirla de forma directa con la propuesta dramática del novel operista mexicano. Dicho sea

6 WeIss, Opera, p. 245. 
de paso, Cavalleria se había estrenado en México un año antes, se repetiría en la temporada y resultaba la más afín en cuanto a estructuración: un acto, pocos personajes y un argumento extraído de la realidad. En síntesis, Colombo a Santo Domingo carecía del amplio desarrollo parisino y se limitaba a un breve instante de lo cotidiano. Aunque en apariencia ese corte se había extraído de la historia, el 12 de octubre de 1492 se vivía como un acto cotidiano; una propuesta verista que tomaba como bandera una causa social. Según las crónicas de la prensa, el aroma de Cristóbal Colón se respiraba en el ambiente y transitaba con descaro en las calles de la ciudad de México.

Si la lectura en conjunto parecía atrevida, el crítico Zil registró -antes de la representación- que la música de Colombo a Santo Domingo decantaba melodías de la música italiana: Bellini, Donizetti y Verdi. Sonoridad que oscilaba entre Wagner y Beethoven, y a semejanza de Cavalleria Rusticana, todo sucedía en un solo acto que se prolongaba como por una hora y media. ${ }^{7}$ Pero no sólo eso, el diario El Universal publicó, el mismo día de la representación, las viñetas de Pietro Mascagni y Julio Morales. Al calce de cada ilustración se consignan datos que ayudan a juzgar la recepción de los autores y otros elementos de contraste por demás interesantes. De inicio, se habla de jóvenes compositores. En efecto, resultan estrictos contemporáneos. Después, se exalta la creatividad melódica del compositor italiano: "inspiración que desbordó en raudales de armoniosas notas", para afirmar finalmente que Cavalleria había sido escuchada y aplaudida en sus principales números unos días antes. ${ }^{8}$ Aquí la comparación resulta pedestre, pues a Morales sólo le exaltan una marcha para orquesta -interpretada un año antes como intermedio de la ópera Cleopatra de su padre-y, por supuesto, le desean éxito como debutante.

7 Zil (seud.), “Ópera Mexicana”, El Correo Español (30 sep. 1892), p. 1.

8 “Pietro Mascagni” y “Julio Morales”, El Universal (12 oct. 1892), p. 3. 
La celebración musical quedó enmarcada así, en una representación escénica que resultó expectación pura. El diario católico El Tiempo -por ejemplo- puntualizó elementos trascendentales para incrementar la difusión del espectáculo. Sin entrar en detalles, ilustró la trayectoria del compositor, reimprimió la nota estilística que situaba la música en la sonoridad más vanguardista transcontinental y, al final, describió aspectos escenotécnicos provocativos para despertar la imaginación de los posibles asistentes:

[La decoración] será vistosa y de grande efecto: vegetación tropical, el mar a la vista, naves semejantes a la Pinta, meciéndose en las olas, un eclipse de luna, una tempestad, el hundimiento por causa de una centella de una de esas naves [...]!

Todo esto, cuyos principales elementos se han traído de Europa, podrá ser verdaderamente grandioso y compensarnos de las detestables decoraciones que nos pone a la vista todas las noches el teatro Nacional. Los trajes, como quiera que son de fines del siglo xv, serán caballerescos y marciales, destacándose entre ellos el de Colón, con su majestuoso ropón de terciopelo negro, su airoso tocado y sus insignias de Almirante de Castilla.

El efecto de esos vistosos trajes con los escasos y primitivos de los indios de la isla, formará un curioso y muy teatral contraste. Hay gran demanda de localidades y esperamos que la noche del miércoles, el teatro Nacional presentará un golpe de vista mágico. ${ }^{9}$

El resultado fue fatal. La simbólica conquista mexicana no llegó y la muerte de la obra fue contundente. Las impresiones en la crítica periodística dejan ver incomodidad y desagrado, aunque no se trató de un menoscabo generalizado hacia la función. Claudio Frollo habla de música presuntuosa, incomprensible y demasiado científica; muy elevada para la ignorancia del

9 “Colón en Santo Domingo", El Tiempo (11 oct. 1892), p. 1. 
público. ${ }^{10}$ Más bien, insinúa que la propuesta de Morales resultó poco agraciada para lo que se esperaba de la ópera. El crítico Raff describió una versión más ilustrativa de la recepción:

[...] Bien es verdad que escasearon un poco los aplausos, y que el "Colón en Santo Domingo" desagradó bastante a la minoría inteligente, a juzgar por la reserva y aún el disgusto con que se recibía a cada número de la flamante partitura, y no llegó a conmover al gros public, por más que un grupo de alumnos del Conservatorio, y otro de amigos del joven maestro lo intentasen en más de una ocasión con vivas y arranques de frenesí inoportunos.

Los que no estamos muy versados en la solfa, no podemos dar una opinión científica, sin riesgo de quedar en ridículo acerca de la obra de Julio Morales; eso ya lo harán los inteligentes en la materia, y del imparcial análisis de la crítica resultará mala o buena la obra; pero los que asistimos al estreno de "Colón en Santo Domingo", faltos de las reglas de contrapunto y composición, pero llenos del deseo del experimentar la emoción estética, no llegaremos a investigar las causas por las cuales no fue ésta producida, pero sí tenemos el derecho de decir al joven Morales: Maestro, no nos ha conmovido usted; no nos gusta, en lo general, la música de su "Colón”; el argumento nos parece insípido, los personajes sin vida, sin carácter, maniquíes, en una palabra; las escenas mal combinadas, y la instrumentación y los efectos musicales de mal gusto. ${ }^{11}$

Con excepción de la romanza para tenor, el miércoles 12 de octubre de 1892 -y su repetición un día después en la función a beneficio del tenor Rawner- la representación no gozó de las mieles del triunfo espontáneo. La ópera Colombo a Santo Domingo se retiró de la programación dos días después del

10 Claudio Frollo (seud.), “De oro y azul”, El Universal (19 oct. 1892), p. 3.

11 Raff (seud.), “Impresiones”, El Siglo Diez y Nueve (15 oct. 1892), p. 2. 
estreno. Gioconda habla de una falta de disposición de los artistas, que no tuvieron confianza en la composición. El efecto fue que durante la interpretación "se notaron débiles e inciertos a excepción de Rawner que se hizo aplaudir en [...] la pieza más comprensible de la obra". ${ }^{12}$ Aunque -sigue Gioconda- "en la masa coral como en la orquesta se oyó en la generalidad de la obra tal confusión, que es totalmente imposible formarse un justo criterio de las ideas del compositor". ${ }^{13}$ Así, la muerte inminente de la ópera mexicana del Centenario quedó ratificada por el propio autor:

Casa de Ud. Octubre 14 de 1892.

Sr. Napoleón Sieni

Presente

Muy estimado señor mío:

Por razones de conveniencia práctica que me reservo y en nada se refieren a la Empresa, le suplico a usted me permita retirar de la escena el "Colón”. Más tarde, cuando el gusto por la música seria esté generalizado y uniformado, haré con alguna nueva producción otra tentativa, en la esperanza de ser bien comprendido.

Por ahora, quedo agradecido a la deferencia de usted, a la caballerosidad del distinguido maestro Golisciani, a la buena voluntad de todos los intérpretes de mi composición y a la bondad del público que, haciendo repetir la romanza del tenor y aplaudiendo cinco números de los nueve que forman mi partitura, tuvo a bien la noche del estreno llamarme ocho veces al honor del proscenio.

12 Gioconda (seud.), “Teatro Nacional. Colón en Santo Domingo”, El Diario del Hogar (16 sep. 1892), p. 1.

13 Gioconda (seud.), “Teatro Nacional”, El Diario del Hogar (16 sep. 1892), p. 1. 
Reiterándole a usted mis sentimientos de adhesión y gratitud, b. s. m. su afectísimo.

Julio M. Morales. ${ }^{14}$

Después de la observación externa, conmemoración y tradición parecen haber sido confrontadas con poca efectividad. Si la fiesta y los homenajes al descubridor rebosaron alegría y vitalidad en la celebración de la ciudad, el desenlace operístico reflejó una dirección opuesta. Las señales del daño interno se vislumbran como un requisito indispensable en la valoración del resultado. Para empezar, Gregorio Aldasoro, bajo el seudónimo de Mab y desde su "Carta de los Domingos", describe algo revelador: una justificación de inexperiencia; pero más interesante, se aproxima a la relación título-festividad. La música -apunta el cronista- da muestras de la falta de oficio, pues

[...] en su afán de parecer original y seguir la escuela armónica moderna, ha aglomerado efectos orquestales, con perjuicio de la expresión musical y dejando a las voces, y naturalmente a la acción dramática, como veladas tras aquel exceso de ciencia. Hay frases bellas y oyendo varias veces esa música complicada, y analizándola, es probable que entren algunas reminiscencias de otras obras. ${ }^{15}$

Además, sigue $M a b$, el libreto no tiene las condiciones de una ópera y Cristóbal Colón está en segundo término. Se puede intuir, dada la periodicidad y el tono narrativo, que la columna de Aldasoro tenía lectoras definidas que esperaban cierto contenido, y esta implicación adivina una postura poco objetiva. No obstante, la lectura constituye una invitación a indagar en

${ }^{14}$ Julio Morales, “La ópera Colón en Sto. Domingo", El Tiempo (16 oct. 1892), p. 2.

${ }^{15}$ Gregorio Aldasoro (Mab, seud.), "Carta de los Domingos”, El Nacional (16 oct. 1892), p. 2. 
el argumento y, quizá más atractivo, a evocar la relación con las otras composiciones que le parecen familiares a Mab.

El argumento del napolitano Enrico Golisciani (1848-1919) para Colombo a Santo Domingo se desarrolla en once escenas; una contradicción a la brevedad de la propuesta. ${ }^{16} \mathrm{Al}$ terminar una introducción orquestal disonante se levanta el telón. La partitura puntualiza un paisaje pintoresco en Santo Domingo con exuberante vegetación en 1502. Al fondo, se observa la orilla del mar, un fuerte de madera y a la lejanía el comienzo del bosque; en primer plano, tiendas de campaña militares y una de ellas ostenta el estandarte de la corona española. En escena aparece un grupo de soldados que se regocija por el botín: oro y esclavas. Las indígenas piden piedad. Mirvana (soprano) -la protagonista cautiva- suplica compasión y externa su relación con Zamoro (tenor), el hijo de un cacique indio; todo para implorar su liberación. Los soldados se burlan. Francesco Bodavilla (barítono), gobernador en el Nuevo Mundo, pregunta por qué tanto alboroto. Entre la multitud reconoce a Mirvana e intenta llevársela. Zamoro defiende a su amada. En una frase patriótica, el protagonista echa en cara que los conquistadores vienen a su país a devastarlo; pero, a diferencia de todo lo demás, Mirvana no será suya. Los españoles se burlan, una vez más. Zamoro es amenazado de muerte. A pesar de las risas sarcásticas de los militares, las indígenas cautivas lo encumbran como el elegido; una inspiración autóctona. Bodavilla le impide a Mirvana seguir a su amado. En una nueva sentencia de celebración -por demás curiosa- Mirvana deja en claro que sus acciones traicionan los principios que proclamó Colón. La sonoridad de la palabra Colombo detona la furia del virrey. La ira explota en sus palabras y ciega su juicio; asegura que Colón está preso del otro lado

${ }_{16}$ Julio Morales, Colombo a Santo Domingo, Partitura y Libreto, Ms. 2077, núm. 2189-2194, Fondo Reservado de la Biblioteca Candelario Huízar, Conservatorio Nacional de Música, México. 
del Atlántico e intenta ejercer su poder para reclamarle amor. Mirvana lo rechaza. Bodavilla pretende tomarla a la fuerza; ella se resiste. A la distancia escucha los pasos al cadalso de Zamoro.

Unos cañonazos anuncian la llegada de navíos. En un diálogo que resulta inverosímil Bodavilla se sorprende al ver la flota española y Roldan (bajo), primer juez del Rey en Santo Domingo, se queja de su suerte. Cristoforo Colombo (bajo) bendice a Dios al pisar tierra firme; todos le rinden homenaje. Los indígenas se postran a sus pies. Colombo narra cómo el rey ha reconocido su inocencia y muestra un pliego que le confiere facultades absolutas. En tanto, Mirvana le ha informado de los ultrajes españoles. No tarda mucho en inculpar a Bodavilla, mientras las lágrimas en su rostro traen el recuerdo de su amado Zamoro. Después de un coro que entona la culpabilidad del virrey, Colón ordena poner en libertad al condenado. Pasaje orquestal nocturno que muestra la luna ascendiendo.

El silencio permite planear una acción desesperada: Bodavilla se presenta ante Zamoro para contarle que Mirvana está en amoríos con el mismísimo Cristoforo Colombo. Aquí, el momento más dramático de la trama: Zamoro canta su desdicha y jura que dará muerte a su querida Mirvana. Sin embargo, teme haber sido engañado y pide a los dioses una señal. Los amantes se reúnen. En un dueto amoroso -sin duda de corte operísticoMirvana expresa la imposibilidad de tal traición a su corazón. Zamoro deja en claro que sólo creerá esas palabras si jura ante el cadáver del navegante. El pasaje amoroso se transforma en un trío: Zamoro, atormentado porque ha decidido matar a Colón, a quien considera un ser sobrenatural, y Mirvana dialogando con Colón para persuadirlo de que elimine cualquier incertidumbre. En la escena final, el virrey y el juez se sorprenden al ver a Colón con vida, a pesar de que implantaron la intriga de la infidelidad. Los militares españoles juran defender al descubridor y gritan ¡viva! Los indígenas, en oposición y alentados por Zamoro, proclaman ¡muerte! Roldán y Bodavilla son arrestados y abordan 
un navío que funcionará como prisión. En la tranquilidad de una oscuridad fatal ha crecido una tormenta. Un rayo alcanza la embarcación; los prisioneros mueren. Mirvana corre a los brazos de Zamoro. Los enamorados se reconcilian y todos aclaman a Cristoforo Colombo. Cae el telón (véase la tabla 2).

Si a la distancia el argumento utilizado por Morales parece deficiente, la crítica de la época no fue indiferente y la evaluación resultó implacable. Por ejemplo, en el diario El Siglo Diez y Nueve, el crítico Raff señaló elementos que se extienden desde las deficiencias hasta la utilización de recursos escenográficos ridículos:

[...] Es verdaderamente cursi aquel Bobadilla (que justifica su apellido desde que entra en escena, hasta que lo mata un cohete chino) requebrando de amores a una india gazmoña, en la ribera de un río, con unos arrebatos románticos y una ira de fantoche, que provocan risa. Y lo mismo pasa con ella, y con Colón y con Zamoro o Chamorro, como dice Rawner, que suele pronunciar mal el italiano. La letra de esta ópera podrá ser mala, pero la indumentaria de seguro que lo es. Cada cuadro del “Colón”, con sus coros en semicírculo en el fondo, y sus cuatro partes principales a la orilla del tablado, se parece mucho a esas estampas de viejas colecciones sobre la vida del navegante genovés, que en marcos mal dorados y bajo vidrios polvosos, cuelgan de las paredes de barbería y fondas de barrio. ${ }^{17}$

Si se realiza una síntesis drástica del argumento de la ópera, Colombo a Santo Domingo es una visión de injusticia y opresión que, por hechos naturales, encumbra a Cristóbal Colón como un justiciero divino; nada más. Pero desde la perspectiva operística, el asunto es un imaginario triángulo amoroso que, por falta de creatividad, no logra sorprender. Zamoro y Mirvana tienen una relación que se altera, no por la esclavitud, sino por los

17 Raff (seud.), “Impresiones”, El Siglo Diez y Nueve (15 oct. 1892), p. 2. 


\section{Tabla 2}

ESTRUCTURA ESCÉNICA DE LA ÓPERA COLOMBO A SANTO DOMINGO DE JULIO MORALES

\begin{tabular}{|c|c|c|}
\hline Escena & Primera línea & Dotación \\
\hline & $\begin{array}{l}\text { Introducción: } \\
\text { Avantio Schiave avanti }\end{array}$ & $\begin{array}{l}\text { Orquesta y } \\
\text { Coro }\end{array}$ \\
\hline 1 & Viva il ciel!... & $\begin{array}{l}\text { Coro y } \\
\text { Mirvana }\end{array}$ \\
\hline 2 & Qual tumulto? Che avviene? & \multirow{2}{*}{$\begin{array}{l}\text { Coro, } \\
\text { Bodavilla, } \\
\text { Mirvana y } \\
\text { Zamoro }\end{array}$} \\
\hline 3 & $\begin{array}{l}\text { Mirvana, io!... Scellerati!... } \\
\text { Non ti basta le tranquille nostre terre conquistar? } \\
\text { Ab! ab! è molto gaio il parolaio }\end{array}$ & \\
\hline 4 & $\begin{array}{l}\text { Recitativo y dueto: } \\
\text { Io vo' con lui morir!... } \\
\text { E questa la vostra fe... }\end{array}$ & $\begin{array}{l}\text { Mirvana y } \\
\text { Bodavilla }\end{array}$ \\
\hline 5 & Suonan sul mar quereschi bronzi!... & $\begin{array}{l}\text { Roldán y } \\
\text { Bodavilla } \\
\text { Coro }\end{array}$ \\
\hline 6 & $\begin{array}{l}\text { Gran escena: } \\
\text { Viva Colombo! } \\
\text { Fe Dio lodiamo Creatore del Cielo e della terra } \\
\text { Non a me fido... } \\
\text { Rapite oltraggiate scherzite fummo } \\
\text { Mirvana risporude a l'inchiesta } \\
\text { Signor Cossi ab! l'opera mia... } \\
\text { Ab! Cessa l'era del lutto e del serraggio }\end{array}$ & $\begin{array}{l}\text { Coro } \\
\text { Bodavilla, } \\
\text { Roldán, } \\
\text { Mirvana y } \\
\text { Cristoforo } \\
\text { Colombo }\end{array}$ \\
\hline \multirow[t]{2}{*}{7} & $\begin{array}{l}\text { Recitativo y dueto: } \\
\text { Non m'inganni signor } \\
\text { La vendetta m'appeghera }\end{array}$ & $\begin{array}{l}\text { Zamoro y } \\
\text { Bodavilla }\end{array}$ \\
\hline & Intermedio & Orquesta \\
\hline 8 & Note che scendi livida nunzia di nembia & Zamoro \\
\hline 9 & $\begin{array}{l}\text { Recitativo y dueto: } \\
\text { Lasciami! Lasciami! }\end{array}$ & $\begin{array}{l}\text { Mirvana y } \\
\text { Zamoro }\end{array}$ \\
\hline 10 & $\begin{array}{l}\text { Terceto: } \\
\text { Perché recedi?... }\end{array}$ & $\begin{array}{l}\text { Mirvana, } \\
\text { Zamoro y } \\
\text { Colombo }\end{array}$ \\
\hline 11 & $\begin{array}{l}\text { Finale: } \\
\text { O rabia! E tu impotente }\end{array}$ & Tutti \\
\hline
\end{tabular}


deseos carnales de Bodavilla. El conflicto se crea porque su lugar -en cuestión amatoria- es suplantado por Colombo, al menos en la mente de Zamoro. La cuestión es que Colón y Mirvana tuvieron que enamorarse a primera vista; en el entendido de que el descubridor recién desembarcaba proveniente de España. Por consiguiente, Zamoro tiene el papel de pareja celosa e indecisa. Pero lo más interesante es que Bodavilla se encuentra de principio a fin como personaje clave de la trama: encarcela, ama, desea, conspira, degrada y ostenta el poder. Su muerte resulta irrisoria; acaso un guiño del destino que coloca todo en su lugar.

En el ejercicio de evaluación comparativa, Cavalleria Rusticana es también un melodrama que se centra en el amor a una mujer, Lola. No se debe olvidar que esta ópera se representó unos días antes del estreno de Colombo a Santo Domingo en el Teatro Nacional de la Ciudad de México; además, se trataba de la gran novedad en los teatros europeos. Sin ir más lejos, en marzo de 1892 el diario El Nacional había publicado un artículo del crítico español Antonio Peña y Goñi sobre la representación de esta composición en los teatros de París y Madrid. ${ }^{18}$ Pero de regreso al embrollo amoroso, en Cavalleria el conflicto se establece entre Turiddu, el antiguo amante de Lola, y Alfio, su esposo. Para coincidencia del espectador de la época, también se construye una escena de celos con Santuzza. La gran diferencia es la resolución. Después de un duelo acordado, Alfio da muerte a Turiddu para concluir de forma hiperdramática la obra. Por supuesto, el desarrollo de la escena da tiempo al tenor para despedirse de su madre, celebrar la amistad y degustar el espumoso vino de la región.

Es sugestivo que para el desarrollo narrativo de ambas óperas: el coro -ya sean autóctonos americanos o sicilianos- adquiere un papel protagónico y realza las decisiones de los solistas; el

18 Antonio Peña y Goñi, “La Cavalleria Rusticana”, El Nacional (12 mar. 1892), p. 1. 
momento de mayor lirismo se da en las romanzas de los tenores, Turiddu y Zamoro; y las dos partituras utilizan la introspección -en la taberna o en una noche tropical eclipsada- para reflexionar sobre la ausencia del ser amado. Este último componente, sin duda, resulta un lugar común en los libretos operísticos. Y una vez más, en las dos óperas sendos momentos llegan después de diálogos apasionados en escena, mismos que se dan después de un intermedio instrumental de transición.

Al revisar el manuscrito del libreto de Golisciani-sobre el que trabajó Julio Morales- se esconde una decisión que resulta crucial. La página final revela una enmienda con la indicación "Quadro analogo". Si bien se trata de la misma mano del copista, la versión alterna está escrita en un fragmento de papel adherido; sin lugar a duda, el contenido escrito en la añadidura es el final que se musicalizó y sobre el que se ha discutido previamente. Sin embargo, es posible leer segmentos de la propuesta original del escritor napolitano para concluir la ópera. En la escena final Bodavilla y Roldan abordan el navío, con la variante de que llevan a Mirvana con ellos. En primer plano, el tumulto de sublevación incitado por Zamoro pierde importancia por la súbita detonación de un rayo. La participación de Colombo en el proscenio llega al punto de ocultarse en la excesiva concentración de elementos escénicos. El texto indica: "Colombo a Zamoro, incalzandolo, a mostrandogli prima la nave sommersa, e poi Mirvana morta”. Es decir, Colón se dirige a Zamoro -sin hablar- suplicándole que vea la embarcación sumergida y después a Mirvana muerta. Las palabras -que estarían entonadas dramáticamente- se vuelven devastadoras: "ha perecido el mal y tú, los mataste [...] ¡Inocente!”. La lectura es simple: alterar la trama para favorecer a Colón perjudicó el resultado, desintegró el efecto dramático y la ópera perdió el único aliento de estupefacción.

A fin de adentrarse en cuestiones musicales y al único número reconocido -la romanza de Zamoro-, es necesario considerar 
que la sonoridad esperada en la temporada era la de Verdi. En particular, así lo hace ver la programación de la compañía Sieni, la más próxima al estilo belcantista. La descripción musical con más autoridad que se registró fue la del crítico Elvino. Su percepción es un buen punto de partida para establecer la atmósfera de la representación:

[...] La vista del espectador se sorprende con la aparición de la luna, y tras esos momentos de calma se sucede la llegada de la carabela de Colón, teniendo necesidad el autor de un esfuerzo para seguir el género imitativo en situaciones tan variadas como la escena reclama. Después de esta rumbosa prueba, se manifiesta una plegaria de soprano secundada por el coro femenino.

Todo lo anterior sirve para preparar un cuarteto y concertante de diversos matices, con lo que puede decirse concluye la primera parte.

Queda colocado desde luego un intermedio instrumental que se desenvuelve con una dulce melodía encomendada al violoncello, y pasa rápidamente a las evoluciones de una tempestad.

Una romanza apasionada encomendada al tenor hace el natural contraste, produciendo en el ánimo del auditorio agradable transición. Quizá esta pieza en su estructura melódica sea la más inspirada y de mayor percepción para el público.

También el duetto para soprano y tenor que continúa, es de agradable efecto; y el terceto final para tenor, soprano, barítono y coro, cierra la escena con que la obra concluye no muy a propósito. ${ }^{19}$

El musicólogo Roger Parker describe que los personajes centrales en las óperas tempranas de Verdi tienen una presentación importante como solistas después de haber integrado dos o tres ensambles; pero se trata de una generalización en el entendido

19 Elvino (seud.), “Espectáculos públicos. En la ópera”, El Correo Español (18 oct. 1892), p. 4. 
de que cada ópera tiene peculiaridades. La acción -sigue Parker- suele proceder a un episodio instrumental que expone la situación emotiva. La disposición entre las diferentes secciones cantadas está determinada por la versificación: recitativo, con alternancia de construcción entre siete y once sílabas, o una estructura cantable con versos simétricos. ${ }^{20}$ Por esta razón, tiende a repetir patrones musicales; nada alejado de la tradición conservadora. Los contornos melódicos recurrentes no dan un peso semántico específico al protagonista; simplemente, cohesionan el discurso musical. De forma más específica, determinan lo que Verdi llamaba “tinte”; el color del personaje. Una característica importante es que los motivos melódicos no tienden a la transformación y, a diferencia de la tradición alemana, el cambio constante o la súbita repetición es un efecto vívido del tiempo presente. ${ }^{21}$ Para finalizar, recuerda Parker que la progresión armónica suele ser simple. En esta lógica, la sección de contraste suele anclar la región de la dominante y el regreso a la tonalidad central coincide con el material que da un color al solista.

La escena vir concentra el discurso dramático de Zamoro (véase la tabla 3). Una rápida lectura del texto ejemplifica una estructura rítmica asimétrica. La versificación está lejos de la tradición. Las diferentes secciones que integran el número, por la misma irregularidad, confrontan afectos a partir de velocidad e intensidad en la interpretación asociada a la música. El resultado es la sensación de indecisión que nubla el juicio del personaje. Sin embargo, al pasar a los elementos de construcción melódica, sin duda se asoman componentes de raigambre. Primero, se establece un contorno que da color al sentimiento o personalidad de Zamoro (véase el ejemplo 1). Se trata de una secuencia ascendente por grado conjunto que ilustra la palabra "desciende" en los cc. 8 y 12, para trasladarse al elemento

20 PArker, “Verdi, Giuseppe”, pp. 437-447.

21 Dahlhaus, Nineteenth-Century Music, pp. 206-217. 


\section{Tabla 3}

“ROMANZA DE ZAMORO."

ESTRUCTURA DEL TEXTO DRAMÁTICO; ÓPERA COLOMBO A SANTO DOMINGO (1892) DE JULIO MORALES

\begin{tabular}{|c|c|c|c|}
\hline Indicación & Compases & Texto & Traducción \\
\hline $\begin{array}{l}\text { Andante } \\
\text { cantabile }\end{array}$ & $8-21$ & $\begin{array}{l}\text { Notte che scendi livida } \\
\text { Nunzia di nembi alle } \\
\text { foreste e al mar } \\
\text { O notte! O notte! } \\
\text { assolgimi } \\
\text { nell' ombra disonorato } \\
\text { io sono! }\end{array}$ & $\begin{array}{l}\text { Noche que desciende } \\
\text { livida } \\
\text { Mensajera de nubes } \\
\text { lluviosas } \\
\text { en el bosque y el mar } \\
\text { ¡Ob noche! } \\
\text { aniquílame } \\
\text { en la sombra estoy } \\
\text { deshonrado }\end{array}$ \\
\hline Allegro & $21-24$ & Ah! muoia!... muoia! & $\begin{array}{l}\text { ¡Ah! ¡Muere!... } \\
\text { ¡Muere! }\end{array}$ \\
\hline Lentamente & $25-30$ & $\begin{array}{l}\text { Si!.... s'e infidele } \\
\text { E sul suo corpo io } \\
\text { spiri! } \\
\text { Si schiuda il suolo, } \\
\text { Il cielo precipiti! }\end{array}$ & $\begin{array}{l}\text { Si... si es infiel } \\
Y \text { sobre su cuerpo } \\
\text { respiro } \\
\text { si se abre el suelo } \\
\text { el cielo se precipita }\end{array}$ \\
\hline Moderato & $31-35$ & $\begin{array}{l}\text { e un abisso inghiotta } \\
\text { l'empia } \\
\text { è il vendicato sposo. }\end{array}$ & $\begin{array}{l}\text { y un abismo se traga a } \\
\text { la impia } \\
\text { es el esposo } \\
\text { reivindicado. }\end{array}$ \\
\hline $\begin{array}{l}\text { Andante } \\
\text { cantabile }\end{array}$ & $38-48$ & $\begin{array}{l}\text { E al mite lume } \\
\text { Degli astri suoi } \\
\text { Sulla sua bocca la mia } \\
\text { I ebbro d' amor!... } \\
\text { E la mia vita } \\
\text { A' baci suoi } \\
\text { Tutta donai } \\
\text { Cieco d'amor!... }\end{array}$ & $\begin{array}{l}\text { y la luz suave } \\
\text { de sus estrellas } \\
\text { en su boca, la mía } \\
\text { reposa } \\
\text { ebrio de amor... } \\
\text { Y mi vida } \\
\text { a sus besos, } \\
\text { todos regalados } \\
\text { ciego de amor }\end{array}$ \\
\hline
\end{tabular}


Tabla 3

“ROMANZA DE ZAMORO.” (concluye)

\begin{tabular}{|c|c|c|c|}
\hline Indicación & Compases & Texto & Traducción \\
\hline $\begin{array}{l}\text { Allegro } \\
\text { con brio }\end{array}$ & $52-56$ & $\begin{array}{l}\text { Ah! muoia s'e infidel! } \\
\text { E un abisso inghiotta } \\
\text { l'empia } \\
\text { È il vendicato sposo! } \\
\text { Muoia! Muoia! }\end{array}$ & $\begin{array}{l}\text { ¡Ab! Muere si es infiel } \\
\text { Y un abismo se traga a } \\
\text { la impia } \\
\text { jes el esposo } \\
\text { reivindicado! } \\
\text { ¡Muere! ¡Muere! }\end{array}$ \\
\hline Recitativo & $59-63$ & $\begin{array}{l}\text { Ma ser forse... } \\
\text { Non è forse } \\
\text { mendare... } \\
\text { Colmi turbar la pace } \\
\text { Del mio spirto } \\
\text { tentò.... }\end{array}$ & $\begin{array}{l}\text { pero tal vez } \\
\text { quizás no es mendigar } \\
\text { llenar la paz contigo } \\
\text { de mi espiritu probó }\end{array}$ \\
\hline Adagio & 68 & $\begin{array}{l}\text { (parlato) forse... } \\
\text { Tu mi guidatemi }\end{array}$ & $\begin{array}{l}\text { tal vez } \\
\text { tú me guíes }\end{array}$ \\
\hline
\end{tabular}

“noche" en los cc. 16 y 17; un recurso retórico contradictorio que se puede interpretar como ingenuo e, incluso, desafortunado. Y, en oposición, un giro de amplia, ondulante y virtuosa línea cierra las frases para mostrar - en conjunto - una larga melodía de estilo belcantista.

Segundo. Al escuchar el "tinte" del personaje y confrontarlo con la sección siguiente, es claro que la pasión consume a Zamoro. El tratamiento dramático se concentra en la acción visceral de dar muerte a su amada. El discurso musical utiliza silencios sorpresivos y disonancias que resuelven en el último tiempo del compás (véase el ejemplo 2). La orquestación, sin ser electrizante o especialmente destacada, utiliza progresiones ascendentes que -por su insistencia- resultan predecibles: trémolo en las cuerdas graves e incremento en la velocidad. El objetivo es dibujar con mejor efectividad el malestar emocional del personaje. De forma sorpresiva, la reflexión llega a Zamoro. 
Ejemplo 1

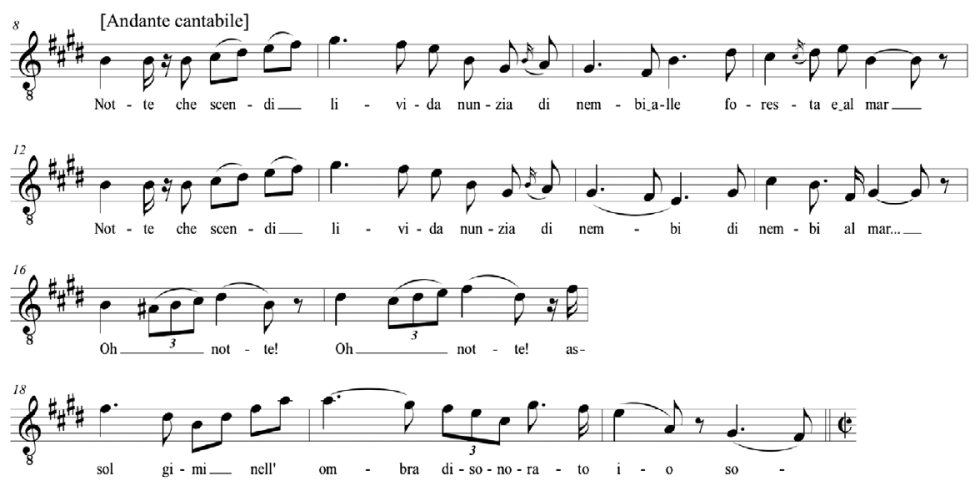

Contorno melódico de la "Romanza de Zamoro", Colombo a Santo Domingo de Julio Morales, cc. 8-20.

\section{Ejemplo 2}
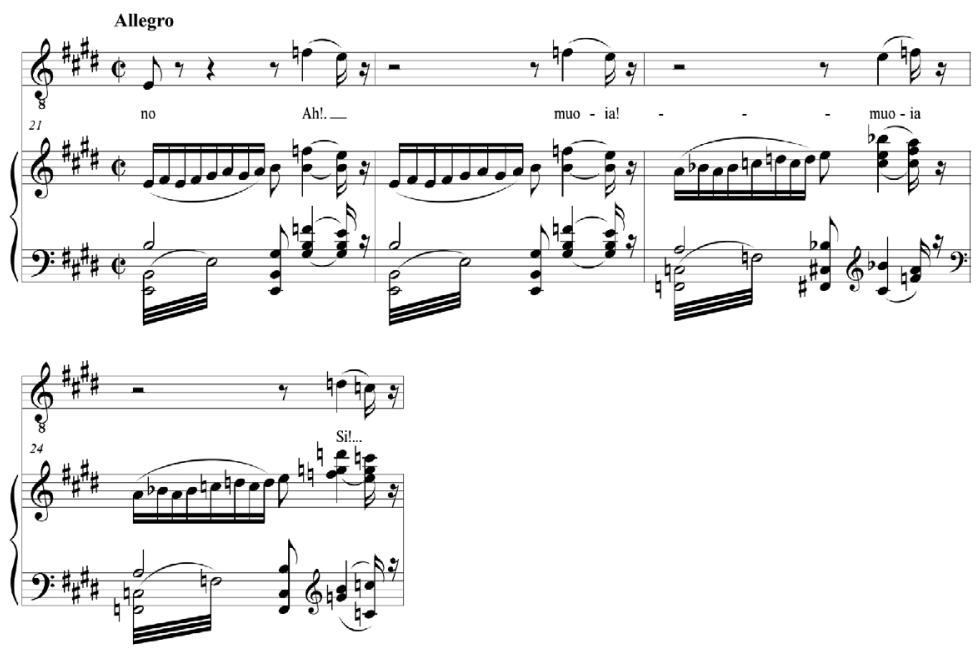

"Romanza de Zamoro", Colombo a Santo Domingo de Julio Morales, cc. 21-24. 
Tercero. La luz de las estrellas ilumina el sentido común; al menos eso parece decir Julio Morales. La utilización de materiales musicales similares lleva a considerar que la condena a Mirvana debe venir por justicia divina y no de propia mano. La progresión armónica regresa a la tonalidad central de mi mayor. Un par de compases sin texto -que recuerdan la línea de inicio- muestran rasgos del estilo verdiano: un acompañamiento arpegiado redundante y el giro de larga melodía belcantista que se escucha sin transformaciones (véase el ejemplo 3). En una decisión acertada -que se puede deducir de las correcciones al manuscrito- el compositor omitió la repetición de la línea melódica y sólo optó por mantener secciones del material melódico; además, el arpegio de acompañamiento cohesiona el discurso musical. El resultado es la omisión de la repetición de la sección integral. El efecto dramático resulta elegante; menos obvio. La extensa línea ondulante, una vez más, permite al oyente recordar el tinte del solista. Pero es importante acentuar una objeción en esta estructuración: el mismo material musical refleja dos contenidos textuales absolutamente diferentes. Es decir, la sonoridad de una extensa y atractiva melodía evoca un paisaje nublado que, en la inmensidad nocturna, bosqueja los perfiles de la naturaleza $\mathrm{y}$, al retomarse, Zamoro se imagina asimismo en los labios candorosos de su querida Mirvana en la misma sonoridad.

Finalmente, un cambio súbito en la tonalidad lleva a una última confirmación del estado psicológico afectado de Zamoro. La melodía retoma dos elementos cruciales: el contorno ondulante -en su parte descendente- y la ira de muerte, que se asocia a silencios que interrumpen el flujo musical; este efecto pasó por su mente apenas unos instantes antes para pensar en la muerte (véase el ejemplo 4). Lo que resulta más atractivo es el tratamiento armónico. La sección está dirigida en do mayor, pero la marcha del acompañamiento elabora de manera incisiva la región de la dominante con cromatismos y acordes aumentados; incluso una cadencia súbita en el c. 54 adelanta la sección de cierre con 
Ejemplo 3

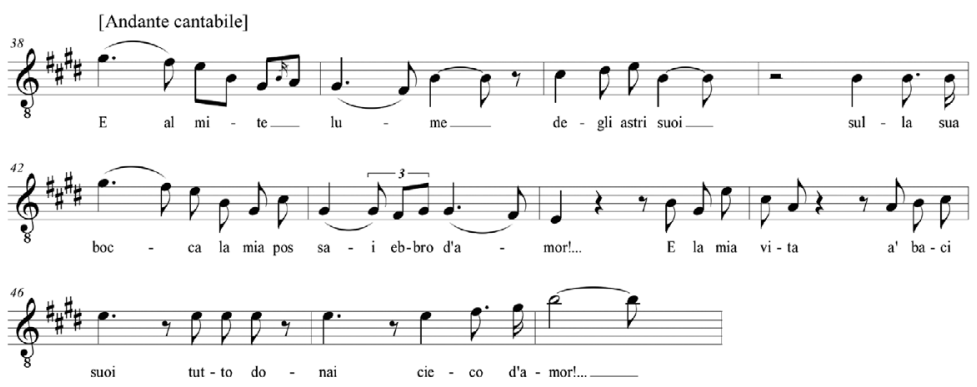

Contorno melódico de la "Romanza de Zamoro", Colombo a Santo Domingo de Julio Morales, cc. 38-48.

un tratamiento recitado. La frase es acompañada en una textura contrastante y facilita la audición por su enorme diferencia (cc. 51-59). El punto climático -y más disonante- llega en la palabra ¡Muere! del c. 56, para concluir la sección cantabile e iniciar el recitativo que da fin a la romanza.

\section{Ejemplo 4}

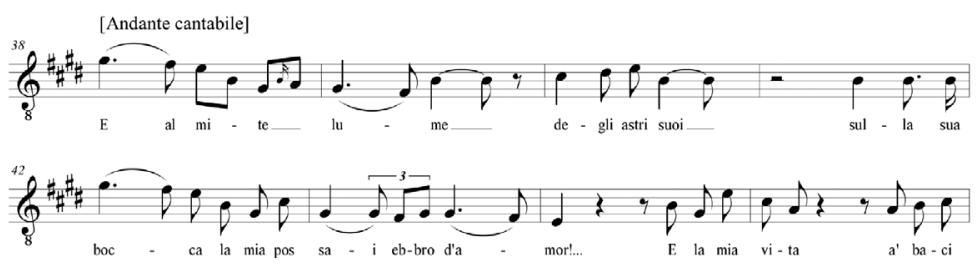

Contorno melódico de la "Romanza de Zamoro", Colombo a Santo Domingo de Julio Morales, cc. 52-56.

Si los elementos musicales no fueran suficientes para llegar a un dictamen contundente de los motivos que llevaron al deceso de Colombo a Santo Domingo, Enrique de Olavarría escribió 
que Julio Morales retiró la ópera "herido en su amor propio" por medio de una carta que se había publicado, "quizá contra su propia voluntad”. ${ }^{22}$ La consumación de este acto resultó en críticas severas y selló la muerte de la ópera del Cuarto Centenario. El recuento de las crónicas de la partitura y la recepción son una invitación morbosa a la revisión del fracaso. La composición no logró el éxito esperado por su mediana manufactura, el lugar que ocupó en la temporada de ópera y, más importante, las decisiones equivocadas para sintetizar tradición y progreso artístico. Sin duda, el mismo Olavarría-que antes había elogiado el trayecto artístico del compositor en un extenso artículo publicado en El Nacional-debe considerarse como un observador mordaz:

[...] cuando Morales quiso defenderse y defender su obra, cosa que a nuestro juicio no debe hacer ningún autor, que puede agradecer el elogio pero no revelarse contra la censura: si ésta fuese racional, fundada y lógica, con ella recibe un bien y según ella corregirá sus defectos; si de esas cualidades carece y sólo la inspiran la envidia y la ignorancia mal intencionada, despréciela y no la conteste como no se contesta el ladrido del perro callejero que padece roña y hambre. ${ }^{23}$

La postura de Olavarría es tan sólo la versión decantada de este pasaje. Para el escritor Luis G. Urbina, la publicación de la misiva era una postura arrogante y jamás debió hacerse pública; en particular porque se sabía que la ópera ya estaba de salida, y después del incidente, se debería considerar más como una fuga. ${ }^{24}$ La lectura lo lleva a proponer que se podía tratar

22 Olavarría y Ferrari, Reseña histórica, pp. 1415-1416.

23 Olavarría y Ferrari, Reseña histórica, pp. 1415-1416. Sobre el artículo biográfico, Olavarría, “Julio M. Morales”, El Nacional (2 oct. 1892), p. 1.

24 Luis G. Urbina (El implacable, seud.), "La retirada de 'Colón'”, El Siglo Diez y Nueve (17 oct. 1892), p. 2. 
de una artimaña de mercadotecnia; "el nervioso cosquilleo de la curiosidad”. Pero la ejecución mostraba contradicciones insalvables: la repetición de la romanza de Zamoro, aplausos a cinco números de la partitura y la llamada al proscenio del autor en ocho ocasiones no deberían ser un fracaso. A manera de paréntesis, indica Urbina, "si el público aplaudió seis números de la partitura, contando con la romanza del tenor, y el maestro Morales salió ocho veces al proscenio [...]", en las cuentas hay un excedente de dos. ${ }^{25}$ Su lectura final resulta lapidaria:

[...] ¿ Cómo se explica, repito, que la obra del Sr. Morales haya sido a la vez muy aplaudida y no comprendida, en el sentido, que según parece, quiere dar el compositor a esta palabra? O el público aplaudió a tontas y a locas, sin saber lo que hacía, y con estupidez inconcebible, o el Sr. Morales se encuentra poco satisfecho con las ocho salidas de marras, y hubiera deseado verse levantado en vilo por un público frenético y hacer su carrera triunfal por la Ciudad, con un reguero de antorchas y ante una muchedumbre arrodillada.

Mas no es ese el más notable error de la carta; el grande, el estupendo, está en las siguientes líneas: Más tarde, cuando el gusto por la música seria esté generalizado y uniformado, haré con alguna nueva producción otra tentativa, en la esperanza de ser bien comprendido.

De cuya afirmación lógicamente se desprenden estas dos razones: o no es verdad que el público, el verdadero público, no un grupo de amigos o un corrillo de parientes, sino esa suma de personalidades que constituye una individualidad compleja, le haya rendido una ovación tan completa al Sr. Morales, o la música del Colón no es música seria. ${ }^{26}$

${ }^{25}$ Luis G. Urbina (El implacable, seud.), "La retirada de 'Colón”, El Siglo Diez y Nueve (17 oct. 1892), p. 2.

${ }^{26}$ Luis G. Urbina (El implacable, seud.), "La retirada de 'Colón”, El Siglo Diez y Nueve (17 oct. 1892), p. 2. 
$\mathrm{Al}$ revisar los mecanismos internos del único número aplaudido, cabe cuestionarse qué pasó con el elemento interpretativo en todo el conjunto. En varios momentos se mencionó que la prensa enfatizaba la mala disposición de los solistas hacia la partitura del mexicano y las limitadas fuerzas de la compañía Sieni. Un vistazo a la recepción de otras funciones puede servir de parámetro para la evaluación de la agrupación artística. Para empezar, Manuel Flores relata cómo la apertura de temporada con la exquisita sonoridad de Verdi preludió - por el resultado obtenido- un ciclo de ópera desafortunado. La profundidad de su crítica merece la repetición extensa:

Comienza el preludio; el canto de amor de Aída debe desprenderse gradualmente y pianísimo como las primeras emociones en un corazón virgen. En lugar de esto se oye, si es que se oye algo, un rechinido áspero y lejano como el de la pata del grillo frotando acompasadamente su élitro. Para que el tema pueda ejecutarse piano y pueda sin embargo oírse; para que en vez de la impresión de un araño produzca la de una caricia, Verdi prescribió doce violines primeros, doce segundos y doce violas. $\mathrm{Y}$ he aquí que la tarea de doce hombres quedó encomendada al Sr. Amaya y a un estimable caballero que estaba a su lado. La orquesta cuenta con catorce violinistas para sobrellevar el peso de tan estupenda partición; es decir, justamente la tercera parte del personal necesario. Dos héroes violinistas, como dos cariátides, cargan con la responsabilidad de hacernos sentir el delicioso Leit Motio [sic] de Amneris; Verdi pide tres grupos de cuatro violoncellos. Los tres contrabajos encordados con cordel no consiguen hacerse oír; para Aída se necesitan lo menos doce.

Ya que de economía se trata y ya que el público lo soporta ¿por qué no generalizar a toda la orquesta la simplificación que Sieni ha introducido en los instrumentos de madera? Con un representante para cada grupo instrumental, la orquesta resultaría más económica y no se oiría ni más ni menos de lo que se oye. Con el tiempo no 
desespero de que oiremos los "Hugonotes" acompañados al piano o el "Anillo de los Nibelungos" interpretados por un organillo mecánico.

Cada grupo instrumental suprimido supone un elemento contrapuntístico menos y a fuerza de suprimir colores en el cuadro acabamos por completarlo todo gris o todo negro. Naturalmente las supresiones abundan [...] Un día de estos Sieni puede muy bien cobrarnos la entrada y no dar la ópera. ${ }^{27}$

Si en la orquesta la falta de sonoridad era un asunto lastimoso, qué se podría esperar del correcto funcionamiento en el coro; un elemento trascendental para resaltar el ambiente emotivo del melodrama. Así, dentro de la misma temporada, se representó La Favorita (1840) de Gaetano Donizetti (1797-1848). Una composición conocida en los escenarios nacionales y que tenía lugares predilectos del público; al menos esperados. Magerit registró que:

[...] la orquesta no llenó del todo su cometido, tal vez por falta de buena dirección. Los coros, siempre desafinan, especialmente el de señoras, cuyo insuficiente número no satisface las exigencias de una ópera, máxime cuando se tropieza con voces viejas y cascadas. De ahí que en los concertantes resulten las desafinaciones, enfriándose con esto el público que no paga por oír gritos estridentes. ${ }^{28}$

Esta observación se podría extender a diferentes momentos de las presentaciones de la Compañía Sieni, pero, en conclusión, Colombo a Santo Domingo no gozó de la mejor interpretación. $\mathrm{Si}$ óperas conocidas y frecuentemente programadas en los teatros de la capital tenían deficiencias tan notorias ¿qué se podría

${ }^{27}$ Manuel Flores (Placable, seud.), "La temporada de Ópera. Aída. Deficiencias de la orquesta”, El Universal (21 sep. 1892), p. 2.

${ }^{28}$ Magerit (seud.), "Espectáculos públicos”, El Correo Español (24 sep. 1892), p. 4. 
esperar de la partitura de un joven compositor mexicano? A la distancia, el asunto no debería de calificarse con la simpleza de condenar a la orquesta, al coro o a los solistas. La muestra de Zamoro permite aventurar un pronóstico más complejo. En 1891, la Compañía Inglesa de Grande Ópera de Emma Juch había irrumpido en los escenarios nacionales con óperas de Wagner, Weber y Beethoven. ${ }^{29}$ Una propuesta que resultó disruptiva para la anquilosada tradición de escuchar melodramas italianos. En la prensa del siguiente año -como lo demostraron el crítico Zil y otros más- se seguía hablando de la sonoridad de Wagner; al parecer, un obstáculo más que debería sortear un autor recién iniciado en el ámbito operístico nacional. Julio Morales decidió reunir elementos de vanguardia y tradición en una sola composición que, por si fuera poco, culminaría la festividad del ingreso de México al mapa mundial de la producción melodramática. En el entendido de que la celebración del descubrimiento de América se seguía en todo el ámbito occidental.

No es difícil imaginar que la cercanía entre Cavalleria Rusticana y Colombo a Santo Domingo estaba en la mente de los oyentes de la época. La dramatización en tiempo presente que proponía el argumento de Colombo a Santo Domingo estuvo lejos de lograr un episodio significativo; la modificación del libreto demeritó el efecto. Algunos aspectos en la estructura tampoco pueden ser descartados como prueba de los recursos modernos que pretendió implementar el autor: un intermedio instrumental para delimitar el ambiente emocional y llevar a buen fin la obra; elementos de localidad -o cotidianidad- en los que se enmarca la trama, y la pretensión de reproducir una sonoridad wagneriana.

Por desgracia para Morales, estos ingredientes fueron mezclados con poca destreza. La sobrevivencia de Mirvana hace

29 Miranda, "Sí, sé que hay sordos...", en Ecos, alientos y sonidos, pp. 137-154. 
inverosímil el desenlace de la ópera y por este simple hecho, el estado atormentado de la sección instrumental queda fuera de lugar, en el entendido de que no proclama nada. De forma similar, en diferentes secciones corales, indígenas y españoles cantan al unísono; una demostración fehaciente de la asimilación cultural que jamás pasaría en el verismo. Finalmente, el uso prolijo de disonancias y el énfasis en la región de dominante, que refuerza la tonalidad, son el resultado sonoro en la emulación wagneriana de Morales. Nada innovador. De la misma forma que es notoria la utilización de notas de paso por semitonos en la romanza de Zamoro, a lo largo de toda la composición se recurre a pasajes que intentan difuminar la construcción tonal. No obstante, siguen la utilización de progresiones melódicas, retardos cadenciales y suspensiones armónicas dramáticas; todos estos elementos estructurales son indicativos de una tonalidad funcional. Y de esta misma forma, existen parámetros ineludibles que se pueden asociar al melodrama y no al verismo. La confirmación de esta idea es la presentación de un finale que involucra a todos los protagonistas para dar conclusión a la obra.

Colombo a Santo Domingo no gustó. La carta de Julio Morales resultó un pretexto para culpar a la audiencia por la incomprensión de su composición. Nadie creyó esta estrategia. La composición partió de la imitación de recursos; un pastiche poco afortunado que, en el momento de máxima tensión, no tuvo el desenlace hiperdramático realista que se esperaba para ensalzar a Cristóbal Colón. Fuera del escenario, la publicación de la carta en la prensa nacional y la negación de Morales para aceptar las deficiencias de su creación, conformaron un certificado de defunción que invitó al descanso perpetuo de la ópera del Centenario. 


\section{REFERENCIAS}

Carmona, Gloria, La música de México. Periodo de la Independencia a la Revolución (1810-1910), vol. 3, México, Universidad Nacional Autónoma de México, 1984.

Dahlhaus, Carl, Nineteenth-Century Music, traducción de Bradford Robinson, Berkeley, University of California Press, 1989.

Miranda, Ricardo, Ecos, alientos y sonidos: ensayos sobre música mexicana, México, Fondo de Cultura Económica, 2001.

Miranda, Ricardo y Aurelio Tello (coords.), La música en los siglos XIX y XX, México, Consejo Nacional para la Cultura y las Artes, 2013.

Morales, Julio, Colombo a Santo Domingo, partitura, Ms. 2077, núm. 21892194, Fondo Reservado de la Biblioteca Candelario Huízar, Conservatorio Nacional de Música.

Olavarría y Ferrari, Enrique de, Reseña histórica del teatro en México, México, Porrúa, 1961, 6 volúmenes.

Parker, Roger, "Verdi, Giuseppe”, en Stanley Sadie (ed.), New Grove Dictionary of Music and Musicians, Londres, Macmillan, 2010.

WeIss, Piero, Opera. A History in Documents, Nueva York, Oxford University Press, 2002. 